\title{
A phase IIa randomized clinical study testing GNbAC1, a humanized monoclonal antibody against the envelope protein of multiple sclerosis associated endogenous retrovirus in multiple sclerosis patients - A twelve month follow-up
}

Tobias Derfuss ${ }^{\text {a }}$, François Curtin ${ }^{\text {b,* }}$, Claudia Guebelin ${ }^{\text {a }}$, Claire Bridel ${ }^{\mathrm{c}}$, Maria Rasenack ${ }^{\mathrm{a}}$, Alain Matthey ${ }^{\mathrm{d}}$, Renaud Du Pasquier ${ }^{\mathrm{e}}$, Myriam Schluep ${ }^{\mathrm{e}}$, Jules Desmeules ${ }^{\mathrm{d}}$, Alois B. Lang ${ }^{\mathrm{b}}$, Hervé Perron $^{\text {b }}$, Raphael Faucard ${ }^{\mathrm{b}}$, Hervé Porchet ${ }^{\text {b,f }}$, Hans-Peter Hartung ${ }^{\mathrm{g}}$, Ludwig Kappos ${ }^{\mathrm{a}}$, Patrice H. Lalive $\mathrm{c}, \mathrm{h}, \mathrm{i}$

\footnotetext{
${ }^{a}$ Neurology Department, Basel University Hospital, Petersgraben 4, Basel, Switzerland

${ }^{\mathrm{b}}$ GeNeuro SA, Chemin des Aulx 18, CH 1228 Plan-les-Ouates, Geneva, Switzerland

${ }^{c}$ Department of Clinical Neurosciences, Division of Neurology, Unit of Neuroimmunology and Multiple Sclerosis, Geneva University Hospital, 1211 Geneva, Switzerland

${ }^{\mathrm{d}}$ Pharmacology and Toxicology Division \& Clinical Trial Unit, Geneva University Hospital, Rue Gabrielle Perret-Gentil, 1214 Geneva, Switzerland

e Neurology Department, Lausanne University Hospital, Rue du Bugnon 46, 1011 Lausanne, Switzerland

${ }^{\mathrm{f}}$ Pharmacology Department, University of Pretoria, South Africa

${ }^{\mathrm{g}}$ Neurology Department, Heinrich Heine University, Moorenstrasse 5, D-40225 Düsseldorf, Germany

${ }^{\mathrm{h}}$ Department of Genetic and Laboratory Medicine, Division of Laboratory Medicine, Geneva University Hospital, 1211 Geneva, Switzerland

${ }^{\mathrm{i}}$ Department of Pathology and Immunology, Faculty of Medicine, University of Geneva, 1211 Geneva, Switzerland

* Corresponding author. E-mail address: fc@geneuro.com (F. Curtin).
}

\begin{abstract}
GNbAC1 is a humanized monoclonal antibody targeting MSRV-Env, an endogenous retroviral protein, which is expressed in multiple sclerosis (MS) lesions, is pro-inflammatory and inhibits oligodendrocyte precursor cell differentiation. This paper describes the open-label extension up to 12 months of a trial testing GNbAC1 in $10 \mathrm{MS}$ patients at 2 and $6 \mathrm{mg} / \mathrm{kg}$. The primary objective was to assess GNbAC1 safety, and other objectives were pharmacokinetic and pharmacodynamic assessments. During the extended study, no safety issues occurred in the 8 remaining patients. No anti-GNbAC1 antibodies were detected. GNbAC1 appears well tolerated.
\end{abstract}

Keywords:

Multiple sclerosis; Human endogenous retrovirus; Monoclonal antibody; Clinical trial; Safety 


\section{Introduction}

$\mathrm{GNbAC1}$ is a recombinant humanized $\mathrm{IgG} 4 / \mathrm{kappa}$ monoclonal antibody (mAb) which binds a protein called MSRV-Env expressed by genes from the human endogenous retrovirus type W family (HERV-W) also named "Multiple Sclerosis associated Retrovirus" (MSRV) (Perron et al., 1997).

Several studies have demonstrated links between the expression of MSRV-Env and multiple sclerosis (MS); in particular immunohistochemical analyses of post-mortem brain tissue from MS patients localize the MSRV-Env protein to MS plaques with a higher level of protein expression in active plaques compared to inactive plaques (Mameli et al., 2007; Perron et al., 2012).

In MS pathogenesis, dysregulation of both the innate and adaptive immune systems is considered as the main triggering and/or exacerbating factor. MSRV-Env activates Toll-like receptor 4 (TLR4) and has a pro-inflammatory effect mediated through its interaction with TLR4 in peripheral blood mononuclear cell (PBMC) cultures (Rolland et al., 2006). Another effect of MSRV-Env is the blockade of the oligodendrocyte differentiation necessary for the remyelination process, also mediated by an interaction with TLR4 on oligodendrocyte precursor cells (OPCs) (Kremer et al., 2013). Based on the ability of MSRV-Env to activate the innate immune system and given its direct toxicity on OPCs, MSRV-Env is a relevant therapeutic target for MS.

The mAb GNbAC1 was developed as a MSRV-Env antagonist. Pre-clinical studies showed that GNbAC1 neutralizes the MSRV-Env target (Rolland et al., 2006; Kremer et al., 2014). GNbAC1 had been studied first in a phase I clinical trial in 33 healthy subjects, showing a good safety as well as a linear pharmacokinetics (Curtin et al., 2012). The goals of the present placebo controlled dose escalation study with an open-label extension was to assess the safety profile, immunogenicity, pharmacokinetic parameters and pharmacodynamics of repeated administrations of GNbAC1 at doses of 2 and $6 \mathrm{mg} / \mathrm{kg}$ in MS patients (Derfuss et al., 2014). The results of the open-label extension phase up to 12 months of treatment are presented.

\section{Material and methods}

Briefly, in 2 dose cohorts (doses $2 \mathrm{mg} / \mathrm{kg}$ or $6 \mathrm{mg} / \mathrm{kg}$ of $\mathrm{GNbAC} 1$ ) of 5 patients each, 4 patients were randomized to receive $\mathrm{GNbAC1}$ and one patient to receive placebo for the first administration in a blinded manner, then all patients of each of the two dose cohorts received 11 repeated administrations of GNbAC1 (either at $2 \mathrm{mg} / \mathrm{kg}$ or at $6 \mathrm{mg} / \mathrm{kg}$ ) at 4 week intervals in an open-label setting. A sample size of 10 patients was considered sufficient for the safety objective of this study. Second-ary objectives included pharmacokinetics, pharmacodynamics, brain magnetic resonance imaging (MRI), immunogenicity and expanded dis-ability status scale (EDSS) measurements. The design of the trial is described in more details in Derfuss et al. (2014). The study protocol was approved by the local ethics committees and the Swiss Medicine Agency, Swissmedic.

Blood and urine samples were collected at baseline and at each drug administration. Adverse events (AEs) were recorded at each visit. Brain MRI was performed at screening and 28 days after the first, 6th and 12th drug administrations. EDSS was assessed at baseline and after the 6th and 12th drug administrations. Methods for GNbAC1 measurement, anti-drug antibody detection and MRI techniques are described else-where (Curtin et al., 2012; Derfuss et al., 2014). Descriptive statistics were computed for the pharmacokinetic, safety, and pharmacodynamic data using SAS® Version 9.2 (SAS Institute, Cary, NC, USA). 


\section{Results}

3.1. Demographic characteristics

Ten patients ( 7 males and 3 females; 1 relapsing remitting MS patient, 3 primary progressive MS patients, 6 secondary progressive MS patients) were randomized into the 2 cohorts. Eight patients (1 patient with relapsing remitting MS and 7 patients with a progressive form of MS) completed the extension up to 12 months, 2 were withdrawn after 6 months, and none of them for safety reasons (one patient completed the study before protocol extension approval, the other one withdrew his consent).

\subsection{Drug safety}

Overall, 135 AEs occurred during trial, AEs occurring in more than 10\%of patients are reported in Table 1. Only one serious AE - a biliary pancreatitis in a patient known for recurrent biliary lithiases - was observed and assessed as unlikely related to the study treatment. Nine of 135 AEs were judged to be possibly related to study drug (chorea, orthostatic tremor, chest pain (2), $\gamma$ glutamyl transferase increased, electrocardiogram QT prolonged, blood urea increased, blood creatinine increased and glomerular filtration rate decreased), and all other AEs were considered as un-likely related or unrelated to study drug. During the open-label extension, the most frequent AEs were gait disturbance ( 9 episodes) re-ported by 2 patients in the $2 \mathrm{mg} / \mathrm{kg}$ group and 1 patient in the $6 \mathrm{mg} / \mathrm{kg}$ group, nasopharyngitis ( 8 episodes) reported by 3 patients in the $2 \mathrm{mg} / \mathrm{kg}$ group and 2 patients in the $6 \mathrm{mg} / \mathrm{kg}$ group, and leukocyturia ( 7 episodes) reported by 1 patient in the 2 $\mathrm{mg} / \mathrm{kg}$ group and 2 patients in the $6 \mathrm{mg} / \mathrm{kg}$ group. During the extension to 12 months, no new safety findings were observed compared to those reported before (Derfuss et al., 2014). No infusion reactions and no hypersensitivity were observed. There were no particular safety signals and no dose-associated trend for safety risks.

\subsection{Pharmacokinetics}

The repeated administration pharmacokinetics of GNbAC1 was characterized by a mean elimination half-life of 37 days and 27 days for the $2 \mathrm{mg} / \mathrm{kg}$ and the $6 \mathrm{mg} / \mathrm{kg}$ doses, respectively. The pharmacokinetics of GNbAC1 was dose-linear. The steady-state was reached after the fourth or fifth administration. Accumulation ratios (ratio of concentrations at Day 113 over Day 29) were between 2.9 and 3.5 for the 2 and the $6 \mathrm{mg} / \mathrm{kg}$ doses respectively.

$\mathrm{GNbAC1}$ concentration in the cerebrospinal fluid (CSF) was assessed in one subject dosed at 6 $\mathrm{mg} / \mathrm{kg}$ one month after the last drug administration and the CSF/serum concentration ratio of GNbAC1 was $0.2 \%$. There was no evidence of anti-drug antibody production against GNbAC1 during the whole study duration.

MRI and EDSS data are presented as Supplementary material. 
Table 1. Treatment emergent adverse events in a single dose phase and in the 12-month open label extension, observed in more than $10 \%$ of patients, by system organ class (SOC) and preferred term (PT).

GnbAC1

Single dose phase ${ }^{\mathrm{a}}$

SOC

Adverse events

(AE)

AE leading to

discontinuation

SAE

Repeated dose

phase

Adverse events

(AE)

$\mathrm{AE}$ leading to

discontinuation

SAE

PT

Placebo $2 \mathrm{mg} / \mathrm{kg} \quad 6 \mathrm{mg} / \mathrm{kg} \quad$ Overall

$$
(n=2) \quad(n=4) \quad(n=4) \quad(n=10)
$$

n

n

$\mathbf{n}$

$\mathbf{n}$

$\begin{array}{llll}2 & 3 & 4 & 9\end{array}$

$\begin{array}{llll}0 & 0 & 0 & 0\end{array}$

$\begin{array}{llll}0 & 0 & 0 & 0\end{array}$

$\begin{array}{llcccr}\begin{array}{l}\text { General dis. \& } \\ \text { admin. site cond. }\end{array} & \text { Fatigue } & 0 & 0 & 2 & 2 \\ \begin{array}{l}\text { Infections and } \\ \text { infestations }\end{array} & \text { Rhinitis } & 0 & 1 & 1 & 2 \\ \begin{array}{l}\text { Nervous system } \\ \text { disorders }\end{array} & \text { Headache } & 1 & 1 & 0 & 2\end{array}$

\section{GNbAC1}

$2 \mathrm{mg} / \mathrm{kg} \quad 6 \mathrm{mg} / \mathrm{kg} \quad$ Overall

$(\mathrm{n}=5) \quad(\mathrm{n}=5) \quad(\mathrm{n}=10)$

$\mathrm{n} \quad \mathrm{n} \quad \mathrm{n}$

$\begin{array}{lll}5 & 5 & 10\end{array}$

$\begin{array}{lll}0 & 0 & 0\end{array}$

$\begin{array}{lll}0 & 1 & 1\end{array}$

\begin{tabular}{|c|c|c|c|}
\hline Cardiac disorders & $\begin{array}{l}\text { Sinus } \\
\text { bradycardia }\end{array}$ & 1 & 1 \\
\hline \multirow{3}{*}{$\begin{array}{l}\text { General dis. \& } \\
\text { admin. site cond. }\end{array}$} & Chest pain & 2 & 0 \\
\hline & Fatigue & 1 & 2 \\
\hline & Gait disturbance & 2 & 1 \\
\hline \multirow{3}{*}{$\begin{array}{l}\text { Infections and } \\
\text { infestations }\end{array}$} & Cystitis & 2 & 1 \\
\hline & Nasopharyngitis & 3 & 2 \\
\hline & Rhinitis & 0 & 2 \\
\hline
\end{tabular}




\begin{tabular}{|c|c|c|c|c|c|c|}
\hline Single dose phase ${ }^{a}$ & SOC & PT & $\begin{array}{c}\text { Placebo } \\
(\mathbf{n}=2) \\
n\end{array}$ & $\begin{array}{c}2 \mathrm{mg} / \mathrm{kg} \\
(\mathrm{n}=4) \\
\mathrm{n}\end{array}$ & $\begin{array}{c}6 \mathrm{mg} / \mathrm{kg} \\
(\mathrm{n}=4) \\
n\end{array}$ & $\begin{array}{c}\text { Overall } \\
(\mathbf{n}=\mathbf{1 0}) \\
\mathbf{n}\end{array}$ \\
\hline & \multirow[t]{2}{*}{ Investigations } & $\begin{array}{l}\text { ECG QT } \\
\text { prolonged }\end{array}$ & & 1 & 1 & 2 \\
\hline & & gGT increased & & 2 & 1 & 3 \\
\hline & $\begin{array}{l}\text { Metabolism \& } \\
\text { nutrition disorders }\end{array}$ & Hyperglycemia & & 0 & 2 & 2 \\
\hline & Nervous system & Headache & & 0 & 2 & 2 \\
\hline & disorders & Muscle spasticity & & 1 & 1 & 2 \\
\hline & Renal and urinary & Leukocyturia & & 1 & 2 & 3 \\
\hline & disorders & Proteinuria & & 1 & 2 & 3 \\
\hline
\end{tabular}

${ }^{a}$ Single dose phase data were already presented in Derfuss et al. (2014).

\section{Discussion}

GNbAC1 is a monoclonal antibody targeting MSRV-Env, a protein which may play a critical role in MS by its inflammatory and myelinotoxic properties. After repeated administrations over one year, GNbAC1 appears to be safe, with adverse events mainly related to medical conditions of the patients. In particular, extending treatment over one year did not suggest additional safety risks compared to the initial exposure (Curtin et al., 2012; Derfuss et al., 2014) without evidence of hypersensitivity or infusion reaction, and no induction of immunogenicity was observed.

The repeated administration pharmacokinetic profile of $\mathrm{GNbAC1}$ is in line with the first pharmacokinetic observations (Curtin et al., 2012; Derfuss et al., 2014) and considering its long half-life, $\mathrm{GNbAC1}$ can be administered with a four week schedule. Interestingly, the CSF-blood ratio of $\mathrm{GNbAC} 1$ in one observation was $0.2 \%$ indicating blood-brain-barrier penetration of the $\mathrm{mAb}$; this value is in line with other published values of CSF-blood ratio observed with mAbs administered to MS patients such as those of the anti-LINGO mAb BIIB033 (Tran et al., 2014) or rituximab (Petereit and Rubbert-Roth, 2009).

No inadvertent increase in disease activity was observed in the study, which may be a concern with a new pharmaceutical mode of action as it was observed recently in a trial with atacicept, a recombinant fusion protein that suppresses B-cell function (Kappos et al., 2014). Moreover the mechanism of action of GNbAC1 appears to be devoid of immunosuppressive action, notably as no impact on lymphocyte or monocyte reaction to antigens was observed in the presence of GNbAC1 (Zimmermann et al., personal communication), which may be an effective treatment of MS. 


\section{Conclusion}

In conclusion, repeated doses of GNbAC1 at doses 2 and $6 \mathrm{mg} / \mathrm{kg}$ were well tolerated over 12 consecutive administrations. Pharmacokinetic and pharmacodynamic observations made at 6 months are supported by the 12-month findings. These encouraging results pave the way for a proof of concept study of GNbAC1 in MS patients.

\section{Funding acknowledgment}

Study funding: GeNeuro SA, Geneva, Switzerland. The sponsor participated in the design and interpretation of the study results.

\section{References}

Curtin, F., Lang, A.B., Perron, H., Laumonier, M., Vidal, V., Porchet, H.C., Hartung, H.P., 2012. GNbAC1, a humanized monoclonal antibody against the envelope protein of multiple sclerosisassociated endogenous retrovirus: a first-in-humans randomized clinical study. Clin. Ther. 34, $2268-2278$.

Derfuss, T., Curtin, F., Guebelin, C., Bridel, C., Rasenack, M., Matthey, A., Pasquier, R.D., Schluep, M., Desmeules, J., Lang, A.B., Perron, H., Faucard, R., Porchet, H., Hartung, H.P., Kappos, L., Lalive, P.H., 2014. A phase IIa randomised clinical study of GNbAC1, a humanised monoclonal antibody against the envelope protein of multiple sclerosis-associated endogenous retrovirus in multiple sclerosis patients. Mult. Scler. (Nov 12. pii: 1352458514554052. [Epub ahead of print]).

Kappos, L., Hartung, H.P., Freedman, M.S., Boyko, A., Radü, E.W., Mikol, D.D., Lamarine, M., Hyvert, Y., Freudensprung, U., Plitz, T., van Beek, J., ATAMS Study Group, 2014. Atacicept in multiple sclerosis (ATAMS): a randomised, placebo-controlled, double-blind, phase 2 trial. Lancet Neurol. 13, 353-363.

Kremer, D., Schichel, T., Förster, M., Tzekova, N., Bernard, C., van der Valk, P., van Horssen, J., Hartung, H.P., Perron, H., Küry, P., 2013. Human endogenous retrovirus type W en velope protein inhibits oligodendroglial precursor cell differentiation. Ann. Neurol. 74, 721-732.

Kremer, D., Förster, M., Schichel, T., Göttle, P., Hartung, H.P., Perron, H., Küry, P., 2014. The neutralizing antibody GNbAC1 abrogates HERV-W envelope protein-mediated oligodendroglial maturation blockade. Mult. Scler. (Dec 5. pii: 1352458514560926.[Epub ahead of print]).

Mameli, G., Astone, V., Arru, G., Marconi, S., Lovato, L., Serra, C., Sotgiu, S., Bonetti, B., Dolei, A., 2007. Brains and peripheral blood mononuclear cells of multiple sclerosis (MS) patients hyperexpress MS-associated retrovirus/HERV-W endogenous retrovirus, but not Human herpesvirus 6. J. Gen. Virol. 88, 264-274.

Perron, H., Garson, J.A., Bedin, F., Beseme, F., Paranhos-Baccala, G., Komurian-Pradel, F., Mallet, F., Tuke, P.W., Voisset, C., Blond, J.L., Lalande, B., Seigneurin, J.M., Mandrand, B., 1997. Molecular identification of a novel retrovirus repeatedly isolated from patients with multiple sclerosis. The Collaborative Research Group on Multiple Sclero-sis. Proc. Natl. Acad. Sci. U. S. A. $94,7583-7588$. 
Perron, H., Germi, R., Bernard, C., Garcia-Montojo, M., Deluen, C., Farinelli, L., Faucard, R., Veas, F., Stefas, I., Fabriek, B.O., Van-Horssen, J., Van-der-Valk, P., Gerdil, C., Mancuso, R., Saresella, M., Clerici, M., Marcel, S., Creange, A., Cavaretta, R., Caputo, D., Arru, G., Morand, P., Lang, A.B., Sotgiu, S., Ruprecht, K., Rieckmann, P., Villoslada, P., Chofflon, M., Boucraut, J., Pelletier, J., Hartung, H.P., 2012. Human endogenous retrovirus type W envelope expression in blood and brain cells provides new insights into multiple sclerosis disease. Mult. Scler. 18, 17211736.

Petereit, H.F., Rubbert-Roth, A., 2009. Rituximab levels in cerebrospinal fluid of patients with neurological autoimmune disorders. Mult. Scler. 15, 189-192.

Rolland, A., Jouvin-Marche, E., Viret, C., Faure, M., Perron, H., Marche, P.N., 2006. The envelope protein of a human endogenous retrovirus- $\mathrm{W}$ family activates innate immunity through CD14/TLR4 and promotes Th1-like responses. J. Immunol. 176, 7636-7644.

Tran, J.Q., Rana, J., Barkhof, F., Melamed, I., Gevorkyan, H., Wattjes, M.P., de Jong, R., Brosofsky, K., Ray, S., Xu, L., Zhao, J., Parr, E., Cadavid, D., 2014. Randomized phase I trials of the safety/tolerability of anti-LINGO-1 monoclonal antibody BIIB033. Neurol. Neuroimmunol. Neuroinflammation 1 (2), e18 (Aug 21, doi:). 
Supplementary material: Individual EDSS scores and MRI data at baseline, 6 months and 12 months.

\begin{tabular}{|c|c|c|c|c|c|c|c|c|c|}
\hline \multirow[t]{2}{*}{ GNbAC1 } & \multirow[t]{2}{*}{ Patient } & \multirow[t]{2}{*}{ Sex } & \multirow[t]{2}{*}{ Age (yr) } & \multirow[t]{2}{*}{ MS Form } & \multirow{2}{*}{$\begin{array}{c}\text { Baseline } \\
\text { EDSS }\end{array}$} & \multicolumn{2}{|c|}{6 months } & \multicolumn{2}{|c|}{12 months } \\
\hline & & & & & & EDSS & $\begin{array}{l}\text { MRI change from } \\
\text { baseline }\end{array}$ & EDSS & $\begin{array}{c}\text { MRI change from } \\
\text { baseline }\end{array}$ \\
\hline \multirow[t]{5}{*}{$2 \mathrm{mg} / \mathrm{kg}$} & 1 & male & 46 & SPMS & 4 & 3.5 & stable & n.a. ${ }^{+}$ & n.a. ${ }^{+}$ \\
\hline & 2 & male & 52 & SPMS & 4.5 & 5 & new lesion* & n.a. ${ }^{+}$ & n.a. ${ }^{+}$ \\
\hline & 3 & male & 49 & SPMS & 6 & 6 & stable & 6 & stable \\
\hline & 4 & male & 57 & SPMS & 6 & 6 & stable & 6 & stable \\
\hline & 5 & female & 59 & PPMS & 6 & 6.5 & stable & 6.5 & stable \\
\hline \multirow[t]{5}{*}{$6 \mathrm{mg} / \mathrm{kg}$} & 6 & female & 57 & RRMS & 2.5 & 2.5 & stable & 2 & stable \\
\hline & 7 & male & 62 & SPMS & 3.5 & 3 & stable & 3 & stable \\
\hline & 8 & male & 51 & PPMS & 3 & 3 & stable & 3 & stable \\
\hline & 9 & female & 47 & SPMS & 6.5 & 7 & stable & 6.5 & stable \\
\hline & 10 & male & 65 & PPMS & 6 & 6.5 & stable & 6.5 & stable \\
\hline
\end{tabular}

*New T2 hyper-intense lesion in the cerebellum

${ }^{+}$non available data, patient dropped out after 6 months 